\title{
Smart Cities: Practitioners' Understanding and Expectations
}

\author{
Results from a Qualitative Study in the City of Koblenz
}

\author{
Roman Antoschin \\ Institute for IS Research, University of Koblenz-Landau, \\ Germany \\ romantoschin@uni-koblenz.de
}

\begin{abstract}
Over the last decade, Smart City has become a growing trend in urban development. Cities around the world have developed a Smart City concept and initiated a longer-term transformation in different areas, covered by the Smart City concept. Cities are expecting, among others, that the many potential benefits and improvements through Smart City implementations can reduce urban challenges. Despite this great interest on the part of practitioners and some standardization efforts, different definitions of the term exist in the literature and in practice. Depending on the context, different aspects are focused on, which shape an idiosyncratic understanding of dimensions of Smart City. Beyond that, the understanding of the term in theory and in practice may vary substantially. As a result, there is an inevitable high degree of complexity in the understanding of the term and, consequently, uncertainty among the practitioners. Thus, this study explores practitioners' understanding of Smart City through expert interviews in the city of Koblenz, Germany. The paper provides a first insight into the heterogeneity of the understanding of the term in the context of application and compares it to the basic definitions and conceptual approaches associated with Smart City developments in the academic literature.
\end{abstract}

\section{CCS CONCEPTS}

- Applied computing $\rightarrow$ Computers in other domains; Computing in government; E-government.

\section{KEYWORDS}

Additional Keywords and Phrases: Smart City, urban development, urban planning, digital transformation, practitioners' expectations

\section{ACM Reference Format:}

Roman Antoschin and Maria A. Wimmer. 2021. Smart Cities: Practitioners' Understanding and Expectations: Results from a Qualitative Study in the City of Koblenz. In 14th International Conference on Theory and Practice of Electronic Governance (ICEGOV 2021), October 06-08, 2021, Athens, Greece. ACM, New York, NY, USA, 8 pages. https://doi.org/10.1145/3494193.3494309

Permission to make digital or hard copies of all or part of this work for personal or classroom use is granted without fee provided that copies are not made or distributed for profit or commercial advantage and that copies bear this notice and the full citation on the first page. Copyrights for components of this work owned by others than ACM must be honored. Abstracting with credit is permitted. To copy otherwise, or republish, to post on servers or to redistribute to lists, requires prior specific permission and/or a fee. Request permissions from permissions@acm.org.

ICEGOV 2021, October 06-08, 2021, Athens, Greece

(C) 2021 Association for Computing Machinery.

ACM ISBN 978-1-4503-9011-8/21/10 . \$ \$15.00

https://doi.org/10.1145/3494193.3494309

\author{
Maria A. Wimmer \\ Institute for IS Research, University of Koblenz-Landau, \\ Germany \\ wimmer@uni-koblenz.de
}

\section{INTRODUCTION}

Smart City has evolved over more than a decade as a concept to modernize urban areas. In particular, the advancements in digital technologies such as internet of things, big data analytics or artificial intelligence contributed to a boost of modernizing urban infrastructures and services around the globe [1].

Investigating literature on Smart City, however, unveiled differences in the conceptualization of the term, despite already existing standardization efforts such as the ISO 37122 standard [2] or the ITU U4SSC initiative ${ }^{1}$. While current research developed an understanding and definitions that are more abstract, such conceptualizations do not fully reflect the understanding that practitioners may have at operational level. The scholarly scientific elaborations of the concept Smart City serves as a basis for practitioners in their work to develop and realize a Smart City strategy. However, it is also necessary to investigate the perception, understanding and expectations of practitioners and local politicians towards the concept of Smart City, since a common understanding and aligned expectations are a prerequisite for achieving political commitment and the buy-in of relevant stakeholders toward the massive changes in urban development through Smart City initiatives. This requires a careful examination of the understanding of the Smart City concept in practice in order to understand the different expectations and to be able to carry out effective expectations management.

This paper documents the results of an empirical investigation on what practitioners in the city of Koblenz understand by Smart City, and what expectations they have towards the establishment and implementation of a Smart City strategy. Two research questions guide the study: a) what are practitioners' perceptions and expectations of a Smart City (RQ1); b) how do practitioners' perceptions and expectations differ from the understanding in academic literature (academic-practitioner gap) (RQ2). Finally, lessons for guiding practitioners in the implementation of Smart City solutions along an overarching Smart City strategy are derived.

To answer the research questions, a systematic literature review, guided by Webster and Watson [3], is conducted to summarize the scientific foundations of the Smart City concept from academic literature. The synthesis of literature is documented in section 2 and it provides the foundations for designing the semi-structured interview protocol. To investigate the understanding of Smart City concepts by practitioners, twenty-five semi-structured interviews are conducted in the city of Koblenz, querying the practitioners' understanding, vision, expectations, potentials and risks in the realization, and individual responsibilities of key actors to implement

${ }^{1}$ https://www.itu.int/en/ITU-T/ssc/united/Pages/default.aspx (last access: $9^{\text {th }}$ May 2021) 
Smart City solutions. The results of the empirical analysis are synthesized using qualitative content analysis [4] and are presented in section 3 . The findings from the literature analysis and the empirical research are discussed in section 4 , therewith deriving recommendations for establishing a coherent understanding and expectations management along Smart City strategy formulation and initiative management. The paper concludes in section 5 with a reflection of answering the research questions and with an outlook on future research.

\section{LITERATURE REVIEW ON SMART CITY}

In the following subsections, the key definitions and concepts as well as core aspects of a Smart City as argued in literature are summarized. Along this, commonalities and differences of understandings are examined and synthesized, which build the foundations for the empirical research to analyze the academic-practitioner gap [6].

The literature analysis is based on Webster and Watson [3]. Articles are searched for in literature databases such as ACM Digital Library, Google Scholar and IEEE Digital Library. As keywords for the initial exploration of relevant sources, the following terms and their concatenations and synonyms are primarily used: Smart City, urban development, urban planning, concept, digital transformation. Secondary terms such as individual dimensions, problems, etc. concretized the orientation of the search in the subsequent iterations. Since Smart City is an interdisciplinary field, papers from different research domains are considered. For the identification of primary and secondary literature sources, also the snowball principle as explained by Lecy and Beatty [5] is applied.

\subsection{Definitions of Smart City}

To define the term Smart City, the literature review identifies three major approaches. The first uses spheres of life to determine the content. For instance, Ojo et al. spot "major policy areas for city governments that are usually targeted for transformation within the Smart City context. [The authors identify.... eight primary domains: Economy, Environment, Energy, People (intellectual endowment and skills), Lifestyle (Building), Mobility (Transportation), Technology, Governance" [6, p. 13]. The second approach puts potential objectives at focus. Caragliu et al. describe these as "investments in human and social capital and traditional (transport) and modern (ICT) communication infrastructure fuel sustainable economic growth and a high quality of life, with a wise management of natural resources, through participatory governance" [7, p. 6]. The third approach, e.g. put forward by Gil-Garcia et al., proposes a conceptual framework with core elements (in the categories: Technology and Data, Physical Environment, Society and Government) and their forms or stages of development [8, p. 78].

A number of scholarly work establishes hybrid forms of the before mentioned three foundational approaches by including several aspects in one definition or analysis [1], [9]-[12]. These understandings result in concepts or frameworks that are suitable for describing and further evaluating individual aspects of a Smart City from a specific perspective, which is at focus in the next subsection. Despite these definitions and considerations of the aspects that can constitute a Smart City, and bearing in mind the standardization efforts mentioned in the introductory section, a uniform understanding of the term Smart City is not agreed upon, all the more so in practice [1], [13].

\subsection{Concepts of Smart City}

The literature analysis has shown that most of the definitions and views of a Smart City show (at least partial) congruence with three complementary concepts by describing the same aspects of Smart City. The first concept is put forward by Giffinger et al., who note six dimensions of Smart City: Smart Economy, Smart People, Smart Governance, Smart Mobility, Smart Environment and Smart Living [14]. The described dimensions form application fields of a Smart City, and are referenced in numerous publications (for instance in [1], [7], [13], [15], [16]).

Another concept by Nam and Pardo considers the factors that are influenced or that determine the development: Technology Factors, Institutional Factors and Human Factors [17]. Parallels and references to this can be found in the research of Albino et al. [1], Dameri [18] and Gil-Garcia et al. [8], among others.

An entirely different approach is provided by Zygiaris [19], who implies some kind of hierarchical development stages (layers) to describe a smart city concept and to address different socio-economicpolitical-technical challenges: City (Layer 0, the city as it is), Green City, Interconnection, Instrumentation, Open Integration, Application, and Innovation (Layer 6). This approach is used by other scholars (e.g. [1], [8], [10]) - who partly use different terminology - to include aspects that are described in the individual layers by Zygiaris.

\subsection{Key Aspects of Smart City Stressed in Literature}

Primarily, 'application fields' according to Giffinger et al. [14] are used for differentiation in most theory- and application-oriented literature. What the definitions and perspectives have in common is that these describe development concepts for sustainable, progressive urban growth, which aim to reduce urban challenges [1], [8], [11]. Along these concepts of Smart City, disruptive technologies such as artificial intelligence, big data, and the internet of things [9], [19]-[21] are employed to automate and improve existing activities in application fields and to enable new smart application fields, e.g. smart disaster management planning and execution or smart healthcare [24]. Furthermore, different (mostly) organizational innovations [8], [18], [22], [23], such as the explicit elevation of citizen participation in the urban development process, are part of Smart City concepts.

Like the different application fields potentially embodied and addressed in Smart City, the potential objectives to be achieved may vary. These include the use of ICT and the development of infrastructure [9], reduction of environmental pollution [18], optimization of supply and disposal [10], orientation towards participatory and innovation-promoting urban development [23] and many more (a detailed elaboration would go beyond the scope of this paper due to their diversity and immensity). This implies that government policies should not be considered separately from Smart City implementations as these can be part of a Smart City transformation, 
affect the realization by setting goals at a higher level and at the same time steering the (conditions of) implementation [25].

The literature review demonstrates that the term Smart City is not uniformly and finally defined [1], [13]. Since the practitioners' imagination tends to be strongly influenced by the scope of Smart (City) Government and Governance including information integration, proactive services and openness [26], the heterogeneity of definitions in the literature can challenge strategic decision makers and relevant stakeholders at city level, leading to different expectations of these actors. Next, we therefore investigate the perception and understanding of Smart City from a practitioner perspective, through an empirical study in the city of Koblenz.

\section{INVESTIGATING THE UNDERSTANDING OF SMART CITY BY PRACTITIONERS IN THE CITY OF KOBLENZ}

Point of departure for the empirical study is the aim of the city of Koblenz to develop a Smart City strategy. With around 113,000 inhabitants [27], Koblenz belongs to the large German cities. The city is located in the north of Rhineland-Palatinate at the intersection of the rivers Rhine and Mosel. Topographically, this causes also restrictions in terms of supply and transport infrastructure. From an administrative perspective, Koblenz is divided into 30 city districts and eight local districts [28].

To overcome the pressing socio-economic-political challenges of the city and to generate further positive effects on urban development, the city wants to transform itself into a modern, innovative and sustainable 'Smart' City. While the city of Koblenz does not yet have many advanced Smart City projects, as evidenced by the Bitkom study [29], the German federal government has set up a program 'Smart City model projects' 2 to spur investments to develop German cities and regions towards Smart City. For the city of Koblenz, a challenge is that it currently lacks a unique vision and unique understanding with regard to Smart City. The breadth of definitions in literature as discussed in Section 2 leads to ambiguities among the city's practitioners as to what belongs to a Smart City and what goals they can and shall target. In consequence, a focused expectations management is necessary to streamline the visions and ideas of a Smart City, which meets the overall needs of the relevant constituency of the city.

To support the development of the Smart City strategy in Koblenz, an empirical investigation is conducted to elicit the understanding and expectations that local practitioners have on Smart City. The following subsections present the methodical approach, the interview setup and the results obtained.

\subsection{Methodical Approach}

To identify the aspects associated with a Smart City in the city of Koblenz, twenty-five expert interviews are conducted. The experts interviewed include the primary groups of actors that are directly or indirectly involved in the urban development process: politicians (8), public servants (7), businesses (6) and academics (4).

\footnotetext{
${ }^{2}$ https://www.bmi.bund.de/DE/themen/bauen-wohnen/stadt-wohnen/ stadtentwicklung/smart-cities/smart-cities-node.html, last accessed $5^{\text {th }}$ September 2021
}

The interviews are based on a semi-structured interview protocol, conducted in summer 2020 in person and, due to the COVID-19 pandemic, partly via an online video conferencing system. For protocol purposes, audio recordings are made. Subsequently, the recorded dialogues are transcribed and pre-processed according to the qualitative coding rules of Dresing and Pehl [30]. The comparatively simple transcription rules stipulate that the information level of the gathered content is in the foreground and that a literal transcription takes place initially. In a further processing stage, potential dialects are translated into High German and filler words are removed. All word and sentence breaks, as well as word slurring, are eliminated according to the rules, as long as they have no meaning for the content. Grammatical editing is not intended, and incomprehensible passages are marked as such [30].

The coding of the transcripts is analyzed qualitatively and quantitatively according to the content analysis approach by Mayring [31]. The coding is carried out iteratively, inductively at the beginning and deductively in the further course. Codes are formed from the first analyses and improved in subsequent iterations. For each transcript, the previously identified codes are used and expanded or adapted as needed. As a result, a total of 1959 independent, contentrelated response units are identified from 25 interviews. For the quantitative analysis, these response units are categorized in three iterations so that several levels of evaluation are possible. In the further process, these results form the basis for the development of Smart City solution scenarios informing the Smart City strategy, which are subject of a future publication. The different understandings, ideas and expectations of the practitioners elicited along the interviews result in recommendations to the city of Koblenz.

\subsection{Interview Setup}

Based on the number of interviews and the objectives pursued with the interviewees, a qualitative structure of the interview with open questions is chosen, comprising nine guiding questions, which are supplemented with situational follow-up questions as needed. Figure 1 visualizes the structure of the questionnaire, starting with the understanding and vision experts may have of Smart City (Q1 \& Q2). Further questions regard the challenges experts may perceive along implementing Smart City (Q3), the underlying origin of such challenges (Q4) and their priorities (Q5), the objectives that shall be achieved (Q6), actors responsible for the implementation of Smart City solutions (Q7), and what competencies (Q8) and responsibilities (Q9) are to be set to implement Smart City.

Figure 1 also shows the interdependencies among aspects, e.g. the objectives being determined by the respective understanding and vision of Smart City, or objectives driven by potential challenges that need to be resolved. Consequently, the interviews determine the dimensions, which the Smart City concept for Koblenz should focus on.

\subsection{Findings from Expert Interviews}

Grounded in the diversity and heterogeneity of the definition of a Smart City as elaborated in section 2, the practitioners are initially asked to present their understanding of a Smart City. Figure 2 shows the understanding that the twenty-five interviewees affiliate with Smart City. In total, thirty-six aspects are spotted. Seventeen 


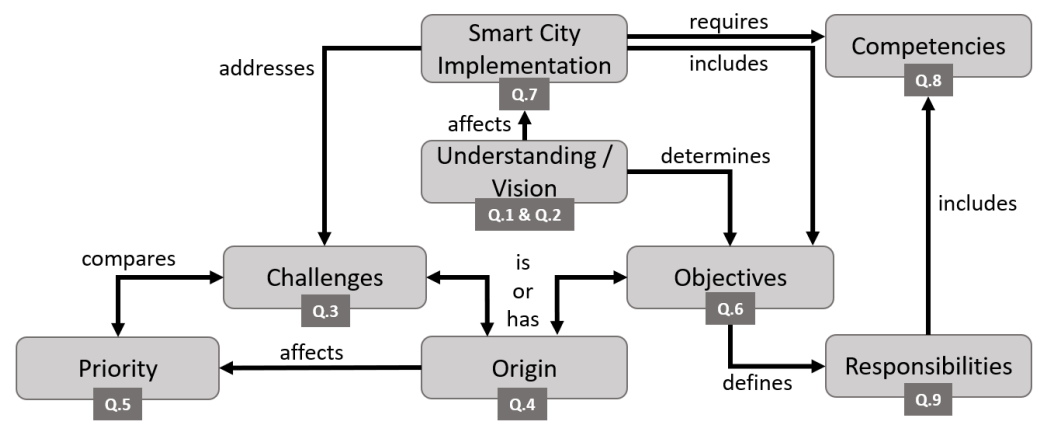

Figure 1: Interview setup with nine guiding questions along eight core interrelated aspects

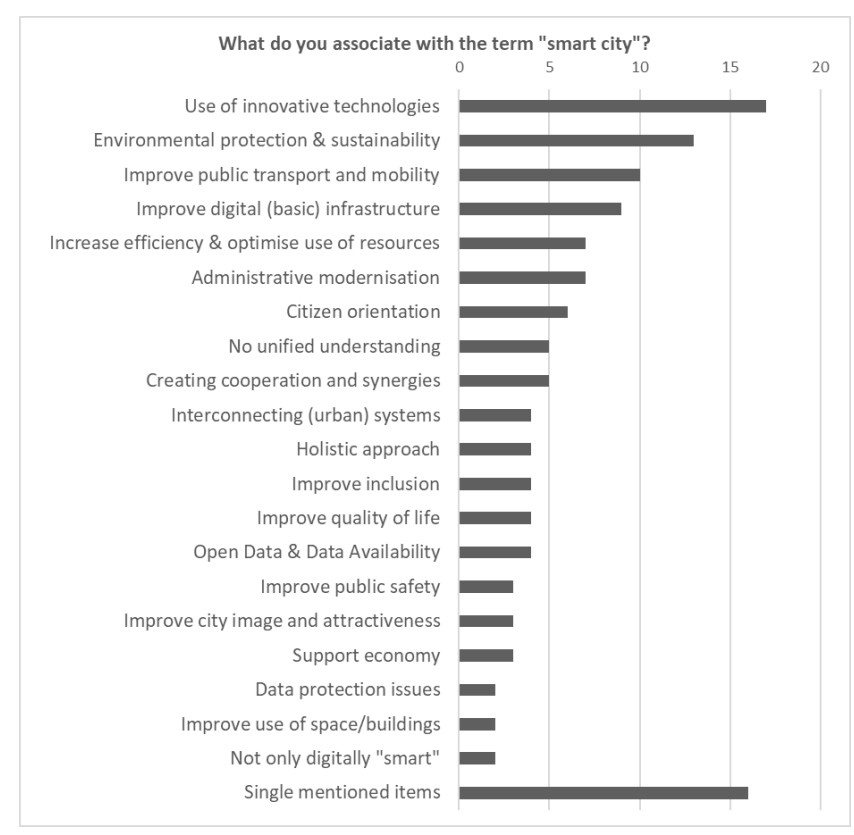

Figure 2: Interview results: Associations with the term "Smart City"

interviewees argue the use of innovative information and communication technologies, regardless of the application fields. Thirteen interviewees associate the pursuit of environmental and sustainability issues as a core objective of a Smart City. Complementary to this is the improvement of public transport and mobility, which is mentioned by ten respondents. Since the city of Koblenz is an important place of work, leisure and education for commuters, the inclusion of the region in the concept development for mobility is emphasized as well.

With regard to the visions of city of Koblenz as a Smart City, the improvement of public transport and mobility scored in the first place. In particular, an integrative transport concept is discussed in more than half of the interviews. In addition, the expansion of cycling (routes) is mentioned, as well as the support of overall mobility through a central public mobility app. Conferring to Giffinger et al. [14], Smart Mobility is an important topic for the city of Koblenz.
City-wide networking and digitalization are likewise important in the visions of the practitioners. Issues mentioned comprise e.g. the creation of a digital twin of the city for planning and organizational purposes, especially for administrative work in the form of simulations (all part of the dimension Smart Governance [14]).

On examining these examples and other categories, it is noticeable that many of the aspects interact with each other or even show congruencies. Despite the iterative formation of categories and thus the systematic elimination of redundancies, not all redundant or congruent categories can be subsumed. The reason for this is that the levels of consideration are also very different. While some of the interviewees define Smart City on the basis of political-strategic goals, other perceptions predominantly relate to concrete technological solutions. As a result, not all categories can be summarized without loss of information. Since several categories are only mentioned once with their specific focus, for the sake of simplicity, these are grouped together in Figure 2 in the category "Single mentioned items". Such items include, among other things, the use of the onceonly principle, the development of platforms, sharing concepts and other elements of a potential Smart City that are at a more detailed level of consideration.

The heterogeneous understanding and the focus on different levels of consideration is also visible when evaluating the concrete solutions that the respondents can imagine for the city of Koblenz. In light of the diversity of the answers, categories are formed in several iterations to be able to compare and evaluate them. By far the most affected aspect is city-wide networking and digitalization, which includes general infrastructure enhancements, the expansion of urban application offerings, and the networking of all systems and sensors to enable aforementioned applications. Complementary to this is the provision and use of open data along the city-wide networking and digitalization, to support mobility, to nurture innovation, to improve public service, and to support citizen participation. The provision and use of open data is seen as a basic prerequisite for numerous Smart City solutions. The expectation of respondents is that a multimodal approach shall ensure simple integration and holism.

Besides the system-related networking, the collaboration and networking among the actors, especially via an exchange platform, is an aspect to be enabled. Innovative solutions are expected that promote innovation and creativity in general. The practitioners mention e.g. the establishment of competence centers, innovation 


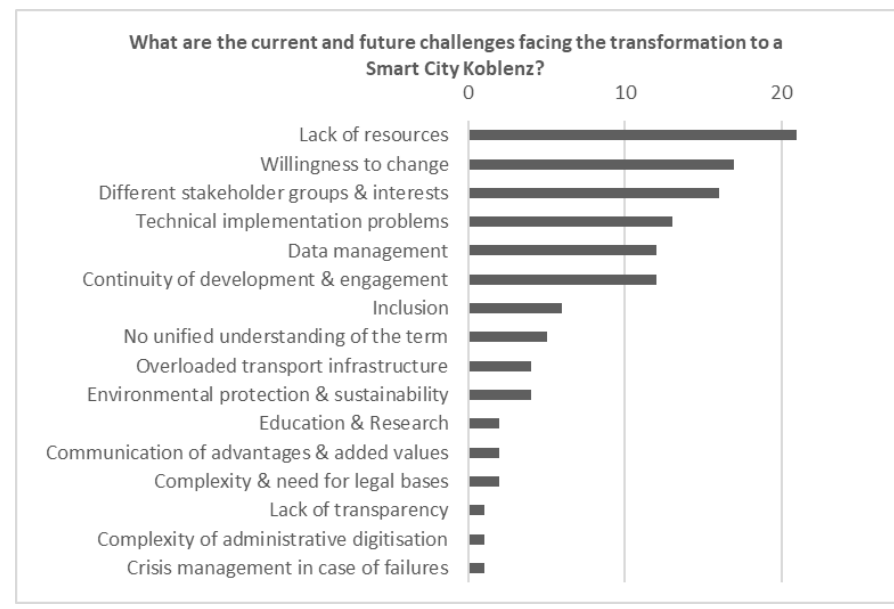

Figure 3: Interview results: Challenges in City of Koblenz

centers and experimental spaces. Noticeable is that most of the answers here also relate directly or at least indirectly to activities in Smart Governance - almost one third of all identified response elements show corresponding reference.

With regard to the biggest challenge to transform the city of Koblenz to a Smart City, 21 respondents named the scarcity of resources. This refers to all forms of resources that are required for the conception and especially the implementation of a Smart City. Accordingly, this challenge includes the lack in the provision and availability of human, knowledge-based and especially financial resources. Figure 3 also shows that, in addition to the scarcity of resources, the willingness to change is perceived as a significant challenge (17 mentions). Among other things, this relates to citizens' fears with regard to issues such as data protection, access to services and the displacement of existing solutions. Consequently, the willingness to use decreases with the degree of uncertainty. The interviews also revealed rigid and bureaucratic structures in city administration as a potential challenge concerning the willingness to change. The practitioners argue this to be intertwined with the lack of willingness to network and cooperate, which inhibits the demand-oriented development of Smart City elements and thus again negatively influences the overall effectiveness of a Smart City concept. To counteract this, a need to create awareness of problems and possible solutions is extracted, which, among other things, justifies the often needed and at the same time challenging conversion of traditional non-digital procedures [11], [32].

As a primary cause for numerous challenges, the lack of commitment and willingness to change could be identified (Figure 4). These are primarily driven by the lack of strategic goals and clear vision to transform into a Smart City. This is also negatively influenced by bureaucratic structures and the resulting insufficient consideration of relevant stakeholder interests (see [15] for similar results).

Some of the practitioners see the lack of plannability (especially for the businesses) as a potential cause of challenges. Thus, economic actors, in particular, miss incentives to participate in the development of a Smart City as well. Without these incentives, there is a potential lack of engagement and sense of responsibility, which in turn is the second major cause of challenges (cf. Figure 4). Consequently, development dynamics, which, according to Hollands [32], is necessary for the continuous motivation of stakeholders, needs yet to be established.

The fact that transformation is understood as an ongoing urban development process is also clearly reflected in the concrete objectives described by the respondents. Even before the city-wide networking and digitalization described above - in this case with a focus on the organizational networking of the actors at all levels to create synergies - the adaptation of the political direction is positioned as the overriding category to transform the City of Koblenz. The multiple responses from individual interview partners are expressed in subcodes, such as heterogeneous but presupposed initial or accompanying action by politics and administration, the inclusion of the region and the basic creation of transparency in public action. According to the interviewees, concrete development plans, strategies and realistic solutions are necessary. Also, a demand for target definitions that are oriented towards the strategies and that serve to justify the solutions is expressed (see also Monzon [15] and Leon [33] for a congruent demand). For the realization of Smart City solutions, the interviewees see the securing of financing (as a political responsibility) as a priority. Hence, the financial means must first and foremost be manifested through a political commitment to urban planning before concrete measures can be taken. This requirement is also a competence that relevant actors must bring in beyond other competencies (cf. Figure 5). The right chart of Figure 5 shows, which actor group shall contribute relevant competencies according to the interviewees.

According to the interviewees, the competencies attributed to the city administration include above all the coordination of the transformation, ensuring the framework conditions as well as internal and external communication. The last point refers in particular to the communication of the benefits of the solutions, assistance for users and the collection of feedback. However, the practitioners also see politics as being at least as involved in the coordination and communication processes as in ensuring the framework conditions.

The interview results show that political actors have to provide tools and resources for the transformation process, besides communication and coordination of the transformation. Likewise, the interviewees see the businesses as being responsible for ensuring the necessary framework conditions. Due to a structurally determined scarcity of resources, ideational and material contributions from private sector are a favorable factor for the development of a Smart City, from which all stakeholders benefit. Moreover, the competencies required from the private sector, namely economic stakeholders, are innovation, creativity and fundamental participation in the transformation process. In parallel, the last-mentioned competence requirements apply equally to the group of citizens from the practitioners' point of view. Conversely, for academia, the practitioners see primarily know-how and the identification of needs as required competencies, although a high degree of knowhow is also expected from private companies. In turn, all groups of actors must be committed and willing to change, whereby the main focus can be placed on politics, administration and citizens according to the interview results. 


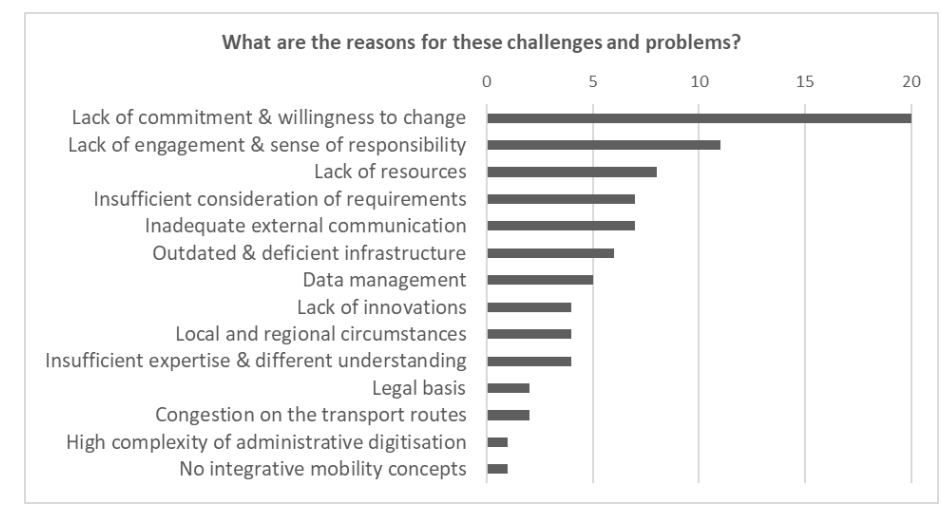

Figure 4: Interview results: Reasons for Challenges

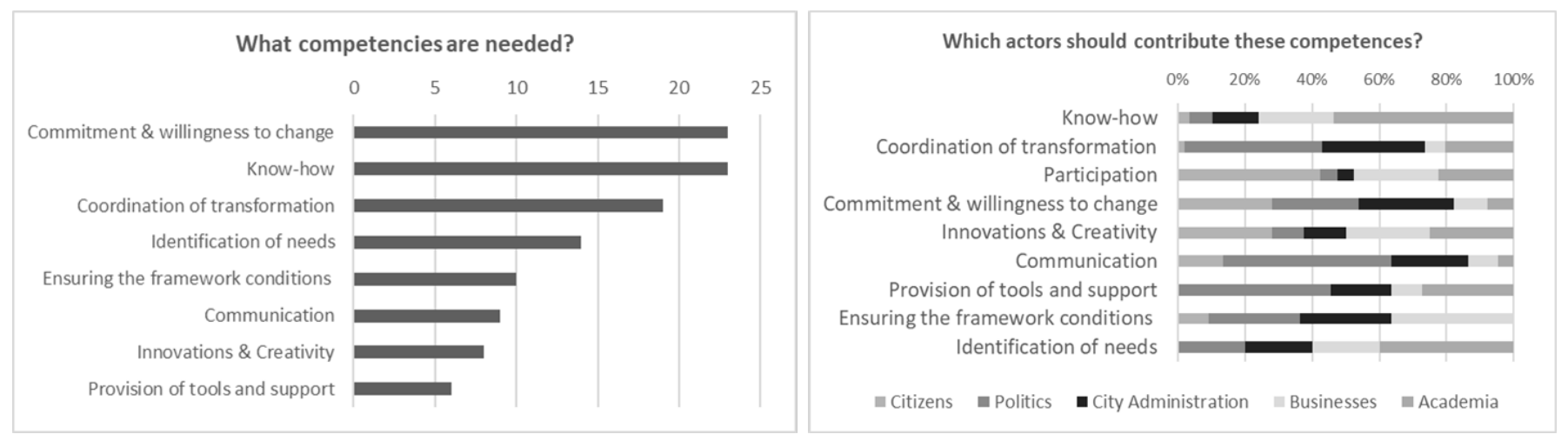

Figure 5: Interview results: Competencies needed to realize Smart City, and actors to contribute these competencies

\section{DISCUSSION AND RECOMMENDATIONS}

Despite individual standardization efforts, the term Smart City is defined in the literature in different and complementary ways. The interviews with practitioners in the city of Koblenz evidence that the term is understood differently by different practitioners. A tendency towards topics from the field of smart government and smart governance is identified, supporting similar findings of AlAwadhi and Scholl, who defined proactive services, interactions of public administration, openness in the sense of administrative action and data as well as smart grids as the core elements of the practitioners' understanding [26]. The findings from the empirical study in the city of Koblenz indicate primarily the application areas of smart governance and smart energy (following the definition of Giffinger et al. [14]) to be affected. While the literature frequently takes an overarching academic-oriented view that focuses primarily on the structuring of the Smart City concept, practitioners require frameworks with more concrete guidance and decision-making support to conceptualize and design the urban transformation process.

The interviews with the practitioners of the city of Koblenz revealed that many different aspects lead to concrete requirements for a Smart City. Among other things, resources are important, which relates closely with the development of basic infrastructure (see also [19]). A Smart City is often associated with the use of technologies [13], but according to the interview results, it is not only to be understood as a technological aspect. Values such as participation in urban development, effective needs and requirements management are also crucial.

Looking at the roles, the success of a transformation to a Smart City cannot be the responsibility of politics or city administration alone - citizens, business and science must also actively participate, which is not obvious from the literature. Nevertheless, in the city of Koblenz, the fundamental political orientation is seen as a key prerequisite for a successful transformation process, a fact that Zygiaris also takes into account in his initial development layers [19]. In summary, the interviews highlight that organizational, political as well as resource-based basic prerequisites must be implemented before planning and implementing concrete Smart City solutions. This leads to the conspicuous fact that the general understanding of the term - which was asked for at the beginning of the paper and primarily includes aspects such as the use of technologies and the pursuit of environmental, sustainable goals - is not as much addressed in the challenges and required competences as perceived by the practitioners. Hence, there is a difference between an ideal understanding according to academia and the real conception of a Smart City by practitioners. One assumption is that the focus in the idealistic conception tends to be oriented towards other successful, usually very progressive case studies. Yet in the practical consideration of cities and regions that have yet to face the transformation 
towards Smart City, other factors such as the individual urban (or rural) characteristics including the particular challenges of individual cities or regions that are perceived as urgent are assessed more important - at least in the case of city of Koblenz.

Consequently, ideal models and model concepts from other cities described in the literature are only transferable to a limited extent or require a careful examination of their transferability. The individual expectations management of responsible practitioners is a preliminary work that shall support the concept development of a Smart City, as these could show significant differences despite the standardization efforts in the literature.

\section{CONCLUSION AND FURTHER RESEARCH}

The research objective of this paper is to investigate practitioners' perceptions and expectations of a Smart City (RQ1) and to examine a possible academic-practitioner gap (RQ2) [34]. This is achieved by reviewing academic literature and by assessing practitioners' understandings and expectations of this concept through a qualitative empirical study in the city of Koblenz. In this paper, we first examine the understanding of the term Smart City utilizing a literature analysis. The literature review highlights that the understanding of the concept Smart City varies [1], [9]-[11]. The term is defined using e.g. fields of action, core elements and/or potential objectives. Furthermore, three basic directions of concepts to conceive and analyze a Smart City are identified in the literature, which are: application fields [14], components and their characteristics [17], and innovation layers [19].

To investigate RQ1, 25 interviews with experts from politics, city administration, citizens, businesses and academia, all living or working in the city of Koblenz are conducted. Heterogeneous understandings and varying objectives are identified in the interviews, some of which are congruent, complementary or cannot be directly compared due to having the focus at different levels of consideration. Consequently, an analysis of potential objectives and the formation of superordinate categories is subject of further research. From a methodological point of view, an intercoder reliability check will improve reliability of the qualitative research, despite extending the interviews to other cities to validate the perception presented in this paper through different cases. Nevertheless, the interview results provide a balanced picture of the practitioners' perception and expectations on Smart City in the city of Koblenz and these constitute the foundation for a continuous expectations management, which is highly recommended for the elaboration of a corresponding Smart City strategy and transformation process.

With regard to RQ2, the interviews evidence that the theoretical definition can deviate from the real observation. Furthermore, at least in the case of the city of Koblenz, the transformation to a Smart City must be initiated by ensuring the framework conditions and by adapting the political alignment, before any categorical concept development can be focused based on the literature and standards.

A limitation of the findings presented in this paper is the geographic scope, as the research is limited to the City of Koblenz. Other cities with different characteristics are subject of further research. Although the results provide usable insights for the city of Koblenz, other cities that are advanced in this topic may have different understandings.
To conclude, this paper discusses definitional approaches for Smart City from an academic stance and identifies commonalities and differences between them. To elaborate the academicpractitioner gap, it provides an insight into the understanding of a Smart City from the perspective of practitioners and, thus, initial expectations management towards Smart City transformation in the context of a specific city. Further research is needed to compare this understanding with that in other cities and to evaluate differences with regard to the respective urban characteristics. Concerning the objectives of a Smart City, there is also a need for a systematic investigation of the relations between these objectives and the individual dimensions of a Smart City.

\section{REFERENCES}

[1] V. Albino, U. Berardi, and R. M. Dangelico, "Smart cities: Definitions, dimensions, performance, and initiatives," f. Urban Technol., vol. 22, no. 1, pp. 3-21, 2015.

[2] K. Midor and G. Płaza, "Moving to Smart Cities Through the Standard Indicators ISO 37120," Multidiscip. Asp. Prod. Eng., vol. 3, no. 1, pp. 617-630, Sep. 2020, doi: 10.2478/mape-2020-0052.

[3] J. Webster and R. T. Watson, "Analyzing the Past to Prepare for the Future: Writing a literature review," MIS Q., vol. 26, no. 2, pp. iii-xiii, 2002.

[4] P. Mayring, Qualitative Content Analysis - Theoretical Foundation, Basic Procedures and Software Solution. Klagenfurth: Beltz, 2014.

[5] J. D. Lecy and K. E. Beatty, "Representative Literature Reviews Using Constrained Snowball Sampling and Citation Network Analysis," SSRN Electron. 7., Feb. 2012.

[6] A. Ojo, E. Curry, T. Janowski, and Z. Dzhusupova, "Designing Next Generation Smart City Initiatives: The SCID Framework," in Transforming City Governments for Successful Smart Cities, Cham: Springer International Publishing, 2015, pp. 43-67.

[7] A. Caragliu, C. Del Bo, and P. Nijkamp, "Smart cities in Europe. J. Urban Technol., vol. 18(0048), pp. 45-59, 2009, doi: 10.1080/10630732.2011.601117.

[8] J. R. Gil-Garcia, T. A. Pardo, and T. Nam, "What makes a city smart? Identifying core components and proposing an integrative and comprehensive conceptualization," Inf. Polity, vol. 20, no. 1, pp. 61-87, Jul. 2015.

[9] M. Angelidou, "Smart city policies: A spatial approach," Cities, vol. 41, pp. 3-11, Jul. 2014.

[10] L. Mora, M. Deakin, and A. Reid, "Strategic principles for smart city development: A multiple case study analysis of European best practices," Technol. Forecast. Soc. Change, vol. 142, pp. 70-97, May 2019.

[11] H. Chourabi et al., "Understanding Smart Cities: An Integrative Framework," in Proceedings of 45th Hawaii International Conference on System Science, 2012, pp. 2289-2297.

[12] B. Mattoni, F. Gugliermetti, and F. Bisegna, "A multilevel method to assess and design the renovation and integration of Smart Cities," Sustain. Cities Soc., vol. 15, pp. 105-119, 2015.

[13] L. Anthopoulos and P. Fitsilis, "Exploring architectural and organizational features in smart cities," in Proceedings of 16th International Conference on Advanced Communication Technology, 2014, pp. 190-195.

[14] R. Giffinger, C. Fertner, H. Kramar, R. Kalasek, N. Pichler-Milanović, and E. Meijers, "Smart cities Ranking of European medium-sized cities," Wien, 2007. Accessed: September 05, 2021. [Online]. Available: http://www.smart-cities.eu/download/ smart_cities_final_report.pdf.

[15] A. Monzon, "Smart cities concept and challenges: Bases for the assessment of smart city projects," in Proceedings of International Conference on Smart Cities and Green ICT Systems (SMARTGREENS), May 2015, vol. 579, pp. 1-11.

[16] C. Thorne and C. Griffiths, "Smart, Smarter, Smartest: Redefining Our Cities," in Smart City How to Create Public and Economic Value with High Technology in Urban Space, D. R. Paola and C. Rosenthal-Sabroux, Eds. Springer, Cham, 2014, pp. 89-99.

[17] T. Nam and T. A. Pardo, "Conceptualizing smart city with dimensions of technology, people, and institutions," in Proceedings of ICEGOV2011 in ACM International Conference Proceeding Series, 2011, pp. 282-291.

[18] R. P. Dameri, "Comparing Smart and Digital City: Initiatives and Strategies in Amsterdam and Genoa. Are They Digital and/or Smart?", in Smart City How to Create Public and Economic Value with High Technology in Urban Space, D. R. Paola and C. Rosenthal-Sabroux, Eds. Springer, Cham, 2014, pp. 45-88.

[19] S. Zygiaris, "Smart City Reference Model: Assisting Planners to Conceptualize the Building of Smart City Innovation Ecosystems," f. Knowl. Econ., vol. 4, no. 2, pp. 217-231, Mar. 2013.

[20] R. E. Hall, B. Bowerman, J. Braverman, J. Taylor, and H. Todosow, "The Vision of A Smart City," Proceedings of 2nd International Life Extension Technology 
Workshop, 2000. Accessed: Sep. 06, 2021. [Online]. Available: https://www.osti. gov/biblio/773961.

[21] T. Bakici, E. Almirall, and J. Wareham, "A Smart City Initiative: The Case of Barcelona" 7. Knowl. Econ., vol. 4, no. 2, pp. 135-148, Jan. 2013.

[22] B. Baccarne, P. Mechant, and D. Schuurman, "Empowered Cities? An Analysis of the Structure and Generated Value of the Smart City Ghent," in Smart City How to Create Public and Economic Value with High Technology in Urban Space, P. R. Dameri and C. Rosenthal-Sabroux, Eds. Springer, Cham, 2014, pp. 157-182.

[23] J. H. Lee, M. G. Hancock, and M. C. Hu, "Towards an effective framework for building smart cities: Lessons from Seoul and San Francisco," Technol. Forecast. Soc. Change, vol. 89, pp. 80-99, Nov. 2014.

[24] A. Ronzhyn and M. A. Wimmer, "Literature Review of Ethical Concerns in the Use of Disruptive Technologies in Government 3.0," in Proceedings of 2019 Thirteenth International Conference on Digital Society and eGovernments, 2019, pp. 85-92.

[25] T. Nam and T. A. Pardo, "Smart City as Urban Innovation: Focusing on Man agement, Policy, and Context," in Proceedings of the 5th International Conference on Theory and Practice of Electronic Governance, 2011, pp. 185-194, doi 10.1145/2072069.2072100.

[26] S. AlAwadhi and H. J. Scholl, "Aspirations and realizations: The Smart City of Seattle," Proc. Annu. Hawaii Int. Conf. Syst. Sci., pp. 1695-1703, 2013, doi: 10.1109/HICSS.2013.102.
[27] Stadt Koblenz, "Monatliche Bevölkerungszahlen Juli 2021," Koblenz, 2021. Accessed: 05 Sept 2021. [Online]. Available: https://www.koblenz.de/downloads/ aemter-und-eigenbetriebe/statistikstelle/bevoelkerung/bevoelkerungsbericht/ monatliche-bevoelkerungszahlen-2021-07.pdf?cid=25ia

[28] Stadt Koblenz, "Statistisches Jahrbuch der Stadt Koblenz 2020," Koblenz, 2020. Accessed: 05 Sept 2021. [Online]. Available: https://www.koblenz.de/rathaus/ verwaltung/statistische-informationen/jahrbuch/.

[29] S. Hampel, "Bitkom Smart City Index 2020," Berlin, 2020. Accessed: Sept 07, 2021. [Online]. Available: https://www.bitkom.org/Smart-City-Index

[30] T. Dresing and T. Pehl, Praxisbuch Interview, Transkription \& Analyse Anleitungen und Regelsysteme für qualitativ Forschende, 4th ed. Marburg: Dr. Dresing und Pehl GmbH, 2012.

[31] P. Mayring, Qualitative content analysis: theoretical foundation, basic procedures and software solution. Klagenfurt: Beltz, 2014

[32] R. G. Hollands, "Will the real smart city please stand up? Intelligent, progressive or entrepreneurial?," City, vol. 12, no. 3, pp. 303-320, 2008.

[33] N. Leon, "Attract and connect: The 22@Barcelona innovation district and the internationalisation of Barcelona business," Innov. Manag. Policy Pract., vol. 10, no. $2-3$, pp. 235-246, 2008.

[34] J. M. Bartunek and S. L. Rynes, "Academics and Practitioners Are Alike and Unlike," f. Manage., vol. 40, no. 5, pp. 1181-1201, Jul. 2014. 